\title{
Contagion and Capaciousness: The Shifting Worlds of Living Models
}

\author{
BY: Gary Genosko
}

ARTICLE INFO:

Volume: 07

Issue: 01

Summer 2021

ISSN: 2459-2943

DOI: 10.18680/hss.2021.0008

Pages: 131-140

Lic.: CC BY-NC-ND 4.0

KEYWORDS:

Living mouse models

Dirty models

Affect theory

Agency, intentionality

\section{ABSTRACT}

T oday, most models are computer-generated simulations

1 of some kind. However, there is a vast world of living models that serve the biomedical industries. Mouse models are discussed here, but in the context of the questions they raise about agency. Living models, it is maintained, can have abundant relations with their laboratory worlds, that is, they have a capaciousness that may be enhanced by processes of dirtying and wilding. The controlled introduction of contagions allows for living models to get messy in a productive way, expanding their lifeworlds as well as those of their handlers. Configurational enunciations of lively assemblages are detailed in terms of more robust microbial encounters, as well as the affective attunements and attachments of the dirty mice initiative in biomedical laboratories.

\section{Introduction}

The approach to modeling recommended in this paper puts the emphasis on activity and change and the onus is on the vibrancy of models, no matter how unlikely, in a world of unfolding relations. This approach defines modeling as a process that is not fully complete or finally defined, even if it is typically contained and constrained by a number of design and operational factors. What is restored to off-the shelf-models, and to living models, specifically lab mice, is respect for their potentiality, despite, in the case of some transgenics, their teleologies. The expectation that models capture something does not entail that they are themselves 
captured by this function alone, or any other function they may actualize; their power to become, no matter how small, is irreducible. Their potentiality is not drained by demonstrations or solutions but persists in multiple imbrications - in the situations in which they appear and reappear and resignify, forcing thought, sharing affect. Lifting the burden of intentions frees the object from the requirements of an exclusively cognitivist demonstration, and attunes one to the force of nonhuman animals, their environments, in highly heterogenous inter-assemblage relations. Opening cracks in worlds of lab mice, it is argued, positively resignifies contagion as a productive force that is semiotically nuanced but also evident in new research processes characterized by messiness, the construction of dirty mice models, and by the re-wilding of living models.

Dirty modeling invokes Michel Serres' sense of the parasite: noise-producing disorder, a disruptive break yet one that is highly productive because "noise gives rise to a new system" (2007:14). Consolidation of the new follows from interruption of the old. For Serres, this transformative force is an entire epistemology in its own right: that of invention sitting at the "intersection of relations" (2007:43). Dirty modeling regarding lab mice arises against the regimes of experimental design that attempt to reduce the parasite to almost nothing in guaranteeing, for instance, pathogen-free samples (pathogens for which the samples have been tested are listed as product attributes). The husbandry skills of lab animal technologists are used to identify and treat ailments, if possible, by eliminating the parasite or its carrier. Yet, these technologists, too, can introduce noise into the system with their affective interests. They can also be makers of noise and purveyors of dirt. The parasite, argues Serres (2007: 79), is "the essence of relation."

\section{Of Modelers}

The idea that models are constructed with physical materials within a bench knowledge tradition has given way to the widespread use of computational modeling involving software that is often commercially available 'off-the-shelf' or in some cases written for a single experimental purpose within a research project. Commercial off-the-shelf software is good for training purposes as it is cost-effective. Its major drawback is that it is not modifiable as no access to the source code is provided and it regularly poses interoperability issues between different proprietary products and packages. The purchase versus write distinction is posed as a distinction between selection and construction: buy or build.

However, for the purposes of this essay, I want to focus on another characterization of this distinction: between low-level identification of an appropriate product 
and high-level or original model construction. Philosophers of science like Michael Weisberg (2007) who make this kind of distinction do so towards two ends: to get modelers, that is, their intentions, into the discussion in order to understand the emphases that individual modelers place upon their creations; and to swerve around the more difficult problem of excluding or diminishing model selection as construction's poor cousin. While the stuff of which models are made vary widely, modelers who do not construct their own models are diminished by Weisberg: "In less path-breaking investigations [than those of Volterra on Adriatic fish species populations and predator-prey balances], modelers often use 'off-the-shelf' models, structures that have already been applied to other phenomena of interest. In such cases, the first stage of modeling involves identifying the appropriate model, rather than explicitly constructing it" (2007: 222, n. 8). Weisberg's passing remark suggests that 'off-theshelf' models are non-specific or multi-purpose and have already served other purposes, and in sense are somehow diminished. And the uses of these 'used' and 'pret à porter' models are connected to lesser breakthroughs.

Weisberg suggests that the question of 'who models?' and the ways in which these intentions may be construed cannot be easily studied when an 'off-the-shelf' model is at issue. One does not answer the 'who' question when the model is identified as a mass-produced commodity with a corporate name, logo, etc. Such models are, apparently, unsigned or unassignable to specific individuals, except by lawyers or within the sealed memories of private corporations. My question moves this discussion in a different direction. What are the surrogate forces that arise in everyday research contexts with commercial and so-called off-the-shelf models? Denied access to intentions, and thus blind to construal issues marking a model's intended scope, emphases, fidelity criteria, etc., my preferred recourse is to acknowledge the anonymity of models, allow for it, and adjust to it, rather than swerve around it.

The first task here is to dissipate the misleading equation of off-the-shelf models and lesser research results, supported rhetorically by the contrastive valorization of construction. Recourse to the lesser is highly recommended by mid-twentieth century pioneers such as Claude Shannon whose interest in building a chess-playing computer focused not at all on grandmaster-level talent but on a "reasonably skillful game" (1950: 49) or, just as Alan Turing noted with regard to the kind of brain a thinking machine might possess, not a powerful one, for sure, but a "mundane brain" (Gleick 2011: 205). Searching for the mundane goes hand-in-hand with denying pride of explanatory place and sovereignty to intentionality, acknowledging, as Jane Bennett states, that intentions are "less definitive of outcomes" than an agential assemblage of things (2010: 32). Thus, the shift towards thing-assemblages away from intentions is a move that also entails a rethinking of 'off the shelf' apparatuses, 
including models. What if off-the-shelf models are allowed to partake in vibrancy and enjoy a vividness hitherto denied to them and captured by their allegedly static, isolated, completeness, and disconnection with the so-called greater, original work of construction?

The second task is to clarify that the focus is on the non-intentionalist, generic solutions, everyday labware, ready-to-use platforms and materials, and their uses in collaborative environments, regardless of whether they are commercial or free, or not. Eschewing the rarified for the widespread and everyday, I want to consider the lessons of overlooked models that serve as vital tools in research activities. This may be accomplished with reference to a number of diverse examples. However, I want to consider living models in their assemblages. Such commonplace models, lacking authors but not trade names and marks, and indeed more often identified with strains, sub-strains, and lab names, are orientation devices: in networked arrays, they display an agential force that contributes to the relationality in which they are found. They are neither neutral nor deterministic, but dynamic and constitutive (Barad 2005: 816). Indeed, this insight helps us to dispense with the idea that any thing or creature is completely and statically pre-formed and deprived of becoming, even a lab mouse. Paraphrasing Karen Barad: "[Models] are not preformed, interchangeable objects that sit atop a shelf waiting to serve a particular purpose. [Models] are constituted through particular practices that are perpetually open rearrangements, rearticulations, and other reworkings" (2005: 816-17). Even off-the-shelf models can enjoy a capaciousness (one of Bennett's felicitous terms now taken up in the affect theory community) that find expression through the relations to whose formation they contribute. In short, there are elements of construction at play even in the use of off-the-shelf models, especially when they are living. This happy admission lifts the dead weight from things like off-the-shelf models and repositions them in terms of their power to intervene. Therefore, I will reject the exclusivity accorded to construction by Weisberg and have recourse to the configurative power (Knuuttila and Merz 2009: 155) of models.

The claim I will advance here is that a semiotics of contagions must be focused on what may be counted among and valued as belonging to the capaciousness displayed by mass-produced living models. The paradigm is the mouse model, this animal platform that has proven to be so valuable in investigating infectious disease pathogenesis. My focus is not on what the platform was designed to do, through inbreeding, outbreeding, xenografting, etc., but what is expressed when something happens that was not intended, even if this something was in some cases predictable given the conditions in which the mouse model lives. To this end, I will look at some of the literature on mouse model health and welfare and attempt to regain in a new way a research direction that may be described as getting messy. 


\section{Living Models}

It is hardly news that standardized and genetically engineered animal models are commercially available and shipped worldwide for use under license from global mouse factories in biomedical research. Donna Haraway famously made the OncoMouse a synecdoche for technoscience and an exemplary example of how scientists mistreat non-human creatures. While Haraway asked us not to neglect generally "rodent feelings and mousy cognition" and to reflect on the "extensive semiotic-corporeal commerce" between species, her tendency is to emphasize how OncoMouse's world is "fully contained" by the laboratory and "fully artifactual space" of technoscience (1997:83, 255). In other words, there is no obvious "adventure of co-becoming" (Stengers 2010: 8 ) between biomedical scientists, student trainees, and technicians and a mouse fabricated to model terminal diseases.

Such living research models come with rigorous product specifications perusable in catalogs like those of Charles River Laboratories (http:/ / www.criver.com), with its array of trademarks (The PoundMouse for obesity research). Obviously, here, strain data is more important than intentionalist analysis. It would be ridiculous to claim that reliance on living animal models precludes 'breakthroughs' in basic biomedical research. But does biomedical research on transgenic nonhumans preclude recognition of obligations demanded by the creatures in terms of the relations formed with the humans who interact with them in experimental practices and the interventions into these relations by the creatures themselves? (Stengers 2010: 17). Such living models are perhaps ironically furthest away from the capacity granted to other non-living models, even things like plastic bags, which pose questions to us and seem vital, for authors such as Gay Hawkins (2010: 128), in their plastic materiality. Yet surely, despite the best efforts of Haraway and Stengers, this is not so, as they themselves prove admirably in their critical responses: they elaborate a relationship with living models by responding to the ethical issues they pose. Going back to the mundane, well below this philosophical 'commerce,' it should be possible to find other responses that bear witness to an animal's relationships that are irreducible to its destiny as a disease model for human scientists. Lab animals force us to notice them - they bite (sometimes each other, sometimes human hands), they excrete (sometimes properly, other times not), they get mixed up with other sets of animals of the same species in a colony, and cause a panic. "The smell is overpowering ... I love it," as one lab technician put it. These animals have the capacity to surprise, even in dying (Anft 2008).

These kinds of entanglements count as the affective force of a living or non-living model. Indeed, perhaps the clearest statement of the foregrounding of relationality among transgenic species and the assemblages in which they participate beyond the lab is transgenic art. In posing ethical questions of companionship, and arguing against animal patents, Eduardo Kac attempted in his GFP Bunny artwork to explore 
"rabbit agency" (Kac 2005: 273), that is, the unique individual and species communicative Umwelten, as well as constructing an artificial transgenic ecology with GFP mice, plants and fish. The exploration of the entanglements with and among transgenics is for Kac a key indicator of the future and for thinkers like Bennett, a way to describe the mutuality of human-nonhuman intimacy, perhaps "porosity" is a better term (2010: 115-16), raising a "more subtle awareness of the complicated web of dissonant connections between bodies [that] will enable wiser interventions into that ecology" (2010: 4).

\section{Configurational Modeling and Enunciative Capacity}

My approach to the mundane world of modeling emphasizes how models are handled. How do models interact? In being arrayed among other models, apparatuses, and programs by buyers, creators, and users, with sundry personnel and automated systems, towards the generation of knowledge, models themselves gain agency in the heterogeneous assemblages which they help to configure and reconfigure in ongoing processes. Boundary drawing and erasing is a restless activity that takes place alongside including, excluding, relating, performing, entangling: "Agency," Barad writes," is not an attribute but the ongoing reconfiguring of the world" (2003: 818).

A configurational model is neither completely tutored by the subject nor disciplined by its object or theory. Rather than speak of the "agency of assemblages," it is complementary to ask about a model's capacity to enunciate within a non-totalizable and collective assemblage consisting of human and non-human components. Hence, the goal is to cast off the linguistic preference for the bickering couple of the subject who speaks and the subject of the statement (constituted by the utterances it receives), in favor of an impersonal, non-individuated force that manufactures subjectifications through the consistency acquired by multiple components (preserving some of the powers of each and together but not as a solidified whole) that arrange themselves around an incorporeal nucleus, less as a set and more by affective contamination. An enunciation is not primarily that of an individual operating at the center or even one dominant assemblage but of a collective assemblage that remains both open and unsorted. Models enunciate their relationality with regard to multiple alterities, both human and non-human. They eschew the centrality of representation and rigor of pure parallelism between themselves and their objects. It is hard to predict effects and designate future states of a distributed agency and a collective enunciative capacity when the assemblage at stake is in "constant variation" and "constantly subject to transformations" (Deleuze and Guattari 1987: 82). The relationality enunciated by a model is not yoked to its object, nor to a subject, and the statements produced in the process sit among other signifying and a-signifying expressions, as well as among the pragmatically reconfigured bodies and things under ordinary working conditions. 


\section{Contagion and Models}

The semiotic overcoding of living mouse models cannot be taken reductively given the approach in this paper. The relationship between inbred (established after 20 generations of brother-sister mating) strains and their congenital issues is often a consideration for model ailments in health and welfare studies. Hundreds of generations of black mice (BL) from the parental strain C57BL have been used widely in biomedicine since the late 1940s. Sub-strains such as C57BL/6, with an added letter or letters to indicate the location of the closed colony, for example, J (Jackson Laboratories) or N (National Institutes of Health), are known to have specific issues; for $\mathrm{J}$, the "unique disease susceptibility" is ulcerative dermatitis (Burkholder 2012). All labs adhere to standard genetic nomenclature, and transgenic strains are built from engineered DNA fragments of the substrain and are indicated following a dash, such as $6-\mathrm{Tg}$, followed by the specific construct. A predictable ailment is compounded with a spontaneous ailment such as the high prevalence of fight wounds (Marx 2013); it is, in addition, a concern to diagnose outbreaks of viral diseases and to act on them in a humane manner. Despite a range of drawbacks, mouse models can be "fine-tuned" (Hendricks 2010) genetically, and some of the problems associated with "closed" colonies remedied through re-naturalization processes. The latter is of great interest in terms of expanding and introducing heterogeneity by opening colonies to enhanced inter-assemblage relations. There are a number of terms used for these practices in the immunological literature, including the wilding approach with bi-directional leanings: bringing into lab colonies mice from pet stores and the wild; moving lab colonies outwards to naturalized outdoor areas (Graham 2021), both resulting in greater and more diverse microbial encounters and thus a robust, wilder microbiome.

Perhaps the most semiotically charged trend is the so-called dirty mice initiative undertaken in the form of a critique of the blind spots of the mid-twentieth century concept of the Specific Pathogen Free colony that is troubled by the introduction of specific pathogens and by the creation of environments conducive to the natural transmission between animals of a diverse range of infectious viruses and bacteria (Masopust 2017). The use of dirty mouse models answers this paper's call to reposition contagions as a semiotically productive and innovative force given to assemblage complexity, variability, and a critique of the drive to cleanliness that negatively constructs any intrusive organism. As one researcher put it when she placed her lab mice in an outdoor enclosure, "they were blissed out, they pulled a couple of all-nighters" (Quoted in Willyard 2018: 17). Ethnographic studies of animal technologists have revealed a range of affective attunements and attachments across species, as well as the stories told about lab animals. These technologists both possess a "skillful gaze" and empathy sometimes 
expressed in considering some mouse models as "pets," something they are taught not to do (Greenhough and Roe 2018). The latter is no mere anthropomorphic gesture but, as the re-wilding initiative suggests, encourages a reflexive recreation of an enriched mouse environment and how this affects, even in transgenic mice, outcomes.

\section{Conclusion}

The activity of modeling involves simplification - a model is always less than that which it models while marking an indirect route to the phenomenon in question; some parts are emphasized, and others are downplayed or ignored. However, too much simplicity detracts from the modeling process and thus leads to a failure to grasp the complexity of the phenomenon at issue, whereas a highly sophisticated and advanced model may be uncritically adopted and misapplied. Simplicity works well with parsimony as plausibility may be achieved through a spare and compact design. In the case of living models, cleanliness and SPF status can overplay simplicity and limit the pertinence of complexity understood as dirt. The evaluation of a model's pertinence returns one to the question of whose needs it meets - those of the modeler or modeling organization (strain and sub-strain constructs by biotech firms), whose intentions and foci put it serves; those of the user (biomedical researchers), into whose problem-solving tasks it provides insight. But when re-wilding occurs, the intentionalist focus on the user's deliberate introduction of defined pathogens opens a process to more random infections and natural transmissions (i.e., parasites that are not part of the model) and inter-assemblage passages of microbes across porous barriers. While it is possible to inquire into the origins of oncomice, for instance, explaining who filed the patent, which researchers won the race, as it were, it is in keeping with our approach that discoveries are not reducible to the intentions of a creator, but "rarely come unilaterally or in a vacuum but rather evolve out of a melting pot of ideas, results, failures, unexpected outcome, and collegial interactions" (Hanahan et al. 2007: 2268). There is tolerance of imperfection and imprecision, then, in living modeling inspired to overcome an overly simplistic clean/dirty dichotomy. It shifts from strictly human intentions to configurational assemblages that distribute affects across themselves and the objects that constitute them. Such configurational enunciations can contain the intense human reactions to smells and the joy of rodent sociality and expanded semiotic breadth of behaviors, but also encompass the ways in which better models are built, how humane animal management advances, even within an industrial-scale production of standard living models, the historic C57Black of the Jackson Laboratories, that Karen Rader (2001: 7) so elegantly describes as being "adapted and constructed for a scientific culture that valued genetically controlled answers to biological and medical questions. Laboratory mice, 
then, are only as human and as natural as they need to be." Overlapping genomes, yet us and not us in a classic Haraway formulation (1997: 82): a model of the human, through cancer; an engineered model of hybridity, and of therapy development for shrinking tumors; a model that is a living mouse. Twenty years later, the boundaries of the natural are being opened up a little to expand the worlds of living models, modifying standards, and enhancing the capacities to enunciate shifting relationalities. Models are gaining in complexity as one clean system becomes a dirtier system, recalling Serres's idea that the parasite increases complexity and is transformative. Building another mouse model turns out to involve recognizing affect as a form of contamination (Wolodzko 2019-20) and not so much welcoming contagion or even praising it, but caring for the disorder it brings and the enriched relations thus entailed. Permitting living models to inhabit zones of approximateness and imprecision and expanding their worlds with as much contingency as possible.

\section{References}

Anft, Michael 2008. Of Mice and Medicine. The Johns Hopkins Magazine 60(4) http:// www.jhu.edu/jhumag/0908web/mice.html

Barad, Karen 2003. Posthumanist Performativity: Toward an Understanding of How Matter Comes to Matter. Signs: J. of Women in Culture and Society 38(3): 801-31.

Bennett, Jane 2010. Vibrant Matter: A Political Ecology of Things. Durham: Duke University Press.

Burkholder, Tanya, et al. 2012. Health Evaluation of Experimental Laboratory Mice. Curr. Protoc Mouse Biology 2: 145-65.

Deleuze, Gilles and Felix Guattari 1987. A Thousand Plateaus. Trans. B. Massumi, Minneapolis: University of Minnesota Press.

Gleick, James 2011. The Information: A History, A Theory, A Flood. New York: Pantheon Books.

Graham, Andrea L. 2021. Naturalizing mouse models for immunology. Nature Immunology 22: 111-17.

Greenhough, Beth and Emma Roe 2018. Attuning to laboratory animals and telling stories: Learning animal geography research skills from animal technologies. Environment and Planning D: Society and Space 37(2): 367-84.

Hanahan, Douglas, et al. 2007 The origins of oncomice: a history of the first transgenic mice genetically engineered to develop cancer. Genes and Development 21: 2258-70.

Haraway, Donna 1997. Modest_Witness@Second_Millennium. London: Routledge.

Hawkins, Gay 2010. Plastic Materialities. In Political Matter: Technoscience, Democracy, and Public Life. Eds. Bruce Braun and Sarah J. Whatmore, Minneapolis: University of Minnesota Press, 119-37. 
Hendricks, Melissa 2010. The Mouse Model: Less than Perfect, Still Invaluable. Johns Hopkins Medicine, Institute for Basic Biomedical Science News. Accessed June 11, 2021. https: / / www.hopkinsmedicine.org/institute_basic_biomedical_sciences/news_ events / articles_and_stories/model_organisms / 201010_mouse_model.html

Kac, Eduardo 2005. Telepresence E Bio Art: Networking Humans, Rabbits, E Robots. Ann Arbor: University of Michigan Press.

Knuuttila, Tarja and Martina Merz 2009. Understanding by Modeling. In: H.W. de Regt, S. Leonelli, and K. Eigner (eds.) Scientific Understanding: Philosophical Perspectives. Pittsburgh: University of Pittsburgh Press, 146-68.

Masopust, David, et al. 2017. Of Mice, Dirty Mice, and Men: Using Mice to Understand Human Immunology. Journal of Immunology 199(2): 383-88.

Marx, James O., et al. 2013. Incidence Rates of Spontaneous Disease in Laboratory Mice Used at a Large Biomedical Research Institution. Journal of the American Association for Laboratory Animal Science 52(6): 782-91.

Rader, Karen 2001. The Mouse's Tale: Standardized Animals in the Culture and Practice of Technoscience. Cabinet 4: 1-9.

Serres, Michel 2007. The Parasite. Trans. Lawrence R. Schehr, Minneapolis: University of Minnesota Press.

Shannon, Claude 1950. A Chess-Playing Machine. Scientific American 182(2): 48-51.

Stengers, Isabelle 2010. Including Nonhumans in Political Theory: Opening Pandora's Box? In: Bruce Braun and Sarah J. Whatmore (eds.) Political Matter: Technoscience, Democracy, and Public Life. Minneapolis: University of Minnesota Press, 3-33.

Weisberg, Michael 2007. Who Is a Modeler? Brit. J. Phil. Sci. 58: 207-33.

Willyard, Cassandra 2018. Squeaky clean mice could be ruining research. Nature 556: 16-18.

Wolodzko, Agnieszka Anna 2019-20. Living within Affect as Contamination: Breathing in Between Numbers. Capacious: Journal for the Emerging Affect Inquiry 2(1-2): 212-24.

\section{AUTHOR}

Gary Genosko Professor of Communication and Digital Media Studies, Faculty of Social Science and Humanities, University of Ontario Institute of Technology, Canada. 